\title{
In Vitro Viability and Cytotoxicity Testing and Same-Well Multi-Parametric Combinations for High Throughput Screening
}

\author{
Andrew L. Niles*, Richard A. Moravec and Terry L. Riss \\ Research Department, Promega Corporation, 2800 Woods Hollow Road, Madison, WI, USA
}

\begin{abstract}
In vitro cytotoxicity testing has become an integral aspect of drug discovery because it is a convenient, costeffective, and predictive means of characterizing the toxic potential of new chemical entities. The early and routine implementation of this testing is testament to its prognostic importance for humans. Although a plethora of assay chemistries and methods exist for 96-well formats, few are practical and sufficiently sensitive enough for application in high throughput screening (HTS). Here we briefly describe a handful of the currently most robust and validated HTS assays for accurate and efficient assessment of cytotoxic risk. We also provide guidance for successful HTS implementation and discuss unique merits and detractions inherent in each method. Lastly, we discuss the advantages of combining specific HTS compatible assays into multi-parametric, same-well formats.
\end{abstract}

\section{INTRODUCTION}

A significant advance in the field of early medicine was Paracelsus' recognition that all compounds have the capacity to be poisonous depending upon dosage [1]. This observation makes toxicity testing a necessary and critical industry practice to identify and define safety thresholds for all new potential chemotherapeutics. The advent of in vitro cytotoxicity testing has greatly streamlined this process and is now considered to be a nearly compulsory activity starting at target validation and continuing through medicinal modification.

Unlike animal-based toxicology testing, there are clearer definitions and greater agreement for what constitutes cytotoxicity in vitro. Classically speaking, a compound or treatment is considered to be cytotoxic if it prevents cellular attachment, causes dramatic morphological changes, adversely affects replication rate, or leads to a reduction in overall viability [2]. It should be noted that the manifestation of these effects is greatly dependent on length of compound exposure and mechanism of cytotoxicity [3].

A host of new assays have been described and utilized which measure biomarkers of cellular stress or specific signaling events more proximal to initial cytotoxic insult (i.e. glutathione, caspases) [4]. These methods offer early indication of potential cytotoxicity, but are typically relegated to secondary screening because they are more difficult to employ as endpoint assays due to the transient nature of the biomarker and kinetic differences associated with cell death progression $[5,6]$. Therefore assay chemistries predicated upon the detection of changes in membrane integrity remain the gold standard for in vitro cytotoxicity testing.

Many methods exist for the assessment of membrane integrity, including several classic dye inclusion, exclusion and lysosomal accumulation techniques [7, 8]. Although well

*Address correspondence to this author at the Research Department, Promega Corporation, 2800 Woods Hollow Road, Madison, WI, USA; E-mail: andrew.niles@promega.com validated, these methods are poorly suited for HTS implementation due to low sensitivity, multiple processing steps or miniaturization problems associated with higher plate densities $[9,10]$. Recent advances in reagent formulations accommodate these miniaturized formats and are fully compatible with automated dispensing systems and integrated detection instruments. These reagents deliver the linearity, sensitivity, and robustness (Z' Values) necessary for properly interrogating large chemical libraries for cytotoxic risk. The most acceptable assay format is known as "add-mixmeasure", whereby reagent chemistry is delivered directly to the test well.

\section{VIABILITY ASSAYS}

Viability assays are designed to measure activities attributable to cellular maintenance and survival. These activities are typically metabolic biomarkers such as ATP and mitochondrial reductase potential, but can include homeostatic "housekeeping" enzyme activities. The underlying assay premise is that these activities are directly proportional to viable cell number after a treatment period. During relatively short incubation periods ( $8 \mathrm{hr}$ or less), a reduction or complete cessation of these biomarker activities is strongly indicative of overt cytotoxicity by catastrophic membrane damage (i.e. primary necrosis) [11]. A reduction in biomarker activity compared to control in longer incubations indicates either a reduction in normal cellular division rate (cell-cycle arrest) or cell death by programmed elimination mechanisms such as apoptosis [12, 13]. Because viability assays measure the relative number of cells remaining after treatment, they offer significant utility even during long compound-contact periods ( $72 \mathrm{hr}$ ).

\section{RESAZURIN REDUCTION}

The reductive capacity inherent within viable cells can be conveniently measured using the redox indicator, resazurin $[14,15]$. Resazurin is soluble in physiologically buffered formulations and can be added directly to growing cultures in a one-step, homogeneous addition. Unlike the tetrazolium chemistries (2,3-bis(2-methoxy-4-nitro-5-sulphophenyl)-5- 
Table 1. Resazurin-Reduction Assay Z'-Factor

\begin{tabular}{|c|c|c|c|}
\hline Cells/Well & Mean Fluorescence after $\mathbf{4 h r}$ at $\mathbf{3 7}^{\circ} \mathbf{C}$ & Standard Deviation & Z'-Factor \\
\hline \hline 0 & 455.28 & 5.76 & 0.8 \\
\hline 500 & 1074.58 & 34.67 & 0.85 \\
\hline 2000 & 3056.88 & 125.37 & 0.87 \\
\hline
\end{tabular}

CellTiter-Blue ${ }^{\circledR}$ (Promega Corporation) was added and incubated with L929 cells dispensed in 384 well plates. $\mathrm{n}=96$ for each cell concentration.

carboxanilide-2H-tetrazolium (XTT), (4-[3-4-iodophenyl]2-(4-nitrophenyl)-2H-5-tetrazolio)-1,3-benzene disulfonate) WST-1, 5-(3-carboxymethoxyphenyl)-2-(4, 5-dimethyl-thiazoly)-3-(4-sulfophenyl) tetrazolium, inner salt (MTS) which measure reductive capacity by colorimetric means, the product of resazurin reduction (resorufin) can also be measured using fluorescence with a fluorometer equipped with $560 \mathrm{~nm}$ excitation and 590nm emission filter set [16-18].

Resorufin product formation as a result of reagent contact with viable cells is accumulative and proceeds as a function of time. Although somewhat dependent upon cell type, metabolic rate and number per well, 2-4 hr of incubation with the reagent is typically sufficient to generate signal windows for adequate statistical discrimination in HTS. (Table 1) Fluorescent resazurin reductase assay chemistries have been adapted to 1536 well formats, but are typically most useful at lesser plate densities (384 and 96) due to practical limitations associated with prolonged incubation periods $[19,20]$.

Resazurin-based chemistries continue to offer significant value for HTS because the reagents are robust and stable, well-validated, and easy to use. The single greatest attribute however, is that resazurin reagents generate amongst the most cost-effective data on a per well basis [21]. The major disadvantages of employing the chemistry are that the reagent is subject to interferences from compounds with inherent reductive capacity (such as ascorbic acid, glutathione, coenzyme A, dithiothreitol etc.) or those with intrinsic fluorescence characteristics [22-24]. Lastly, extended reagent incubations ( $2 \mathrm{hr}$ or longer) may produce toxic affects or augment affects produced from the experimental compound [25].

\section{AMINOPEPTIDASE(S)}

Eukaryotic cells contain a diverse abundance of proteolytic activities which act in a concerted effort to maintain homeostasis. Recently, a constitutive and conserved aminopeptidase-like, proteolytic biomarker profile was identified in mammalian cells that can be harnessed for assessing viability in cell culture [26]. The assay utilizes the cellpermeant protease substrate glycyl-phenylalanyl-aminofluorocoumerin (GF-AFC) that is delivered to wells in a neutral buffer. The substrate, which lacks an amino-terminal blocking moiety (i.e. Boc, Ac, or $\mathrm{Cbz}$ ), can be processed by aminopeptidase(s) within the cytoplasm. The AFC product released after proteolysis of the substrate is proportional to viable cell number. Viability can be measured using a fluorometer equipped with a 380-400nm excitation source and a $505 \mathrm{~nm}$ emission filter.
The selective detection of viable cells by this method is possible because the proteolytic activity towards the GFAFC substrate is dependent upon the continued maintenance of membrane integrity. This live-cell, proteolytic activity decays within seconds after a cytotoxic event, so non-viable cells do not contribute appreciably to fluorescence generation. A 30 minute incubation of reagent and cells at $37^{\circ} \mathrm{C}$ is typically sufficient for generating a workable signal window, but the incubation can be extended without detriment if work-flow scheduling does not permit shorter periods.

A major advantage of this assay is that it can be conveniently multiplexed with other compatible assay chemistries to deliver more per-well information (Fig. 1) [27]. This feature is particularly attractive for normalizing spectrallydistinct fluorescent or luminescent data sets such as genetic report assays [28]. Multiplex applications for viability and cytotoxicity will be handled in greater detail in a later section of this review. Lastly, although red-shifted from much of the problematic coumarin spectrum, the assay is susceptible to fluorescence interferences from test compounds [29]. Additional interferences should be expected from protease inhibitors or from color quenching chemical entities. - CellTiter-Fluor ${ }^{\mathrm{TM}}$ Cell Viability Assay
O Caspase-GI ${ }^{\circledR} 3 / 7$ Assay

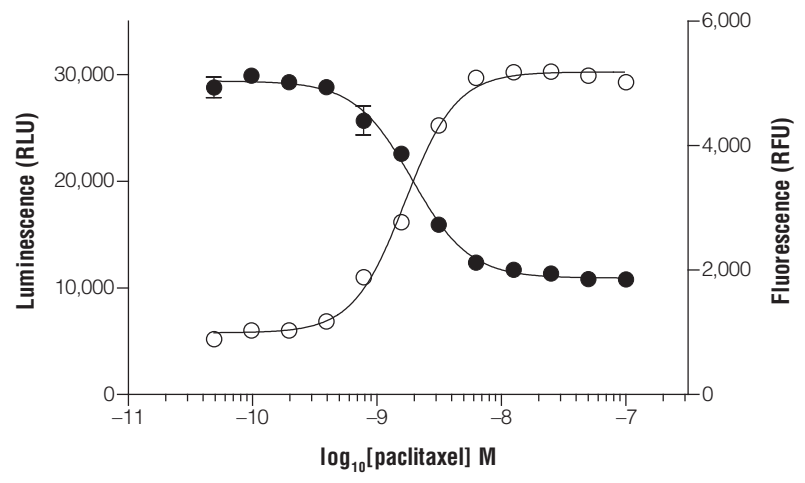

Fig. (1). Aminopeptidase(s) Assay. CellTiter-Fluor ${ }^{\mathrm{TM}}$ (Promega Corporation) was added to Jurkat cells treated for $24 \mathrm{hr}$ with serial dilutions of paclitaxel. Viability was measured, then Caspase-Glo® Reagent added to measure caspase activation.

\section{ATP}

ATP quantification is a widely accepted method for assessing viability because healthy cells contain closely regulated levels of the biomarker [30, 31]. Non-viable cells not only lose the ability to synthesize ATP, but also contain en- 
dogenous ATPases that rapidly deplete the existing ATP. Luciferase reaction chemistry is used to quantify ATP, the limiting reactant, by generation of a luminescent signal that is proportional to viable cell number [32,33].

All commercial ATP quantification reagents contain luciferase enzyme and luciferin substrate supplied with a lytic buffer. Cell lysis is necessary to liberate cellular ATP and is typically facilitated by detergents in the buffer. The most useful formulations for HTS applications also contain thermostable recombinant luciferase and ATPase inhibitors which allow for "glow-type" luminescence that produces a sustained signal with a half-life on the order of $5 \mathrm{hr}[34,35]$. Prolonged maintenance of the luminescent signal allows for batch processing of plates and obviates any inter-plate kinetic variability.

The principle advantages of an ATP assay include that it is currently the most rapid and sensitive HTS method available for assessing viability. For instance, as few as 10 cells can be detected in limiting dilution series of eukaryotic cells within 10 minutes (Fig. 2). The assays also benefit from relatively high signal to background ratios, which enable routine miniaturization into 1536 well formats [36, 37]. Furthermore, luminescence signals are not encumbered by intrinsically fluorescent test compounds [38].

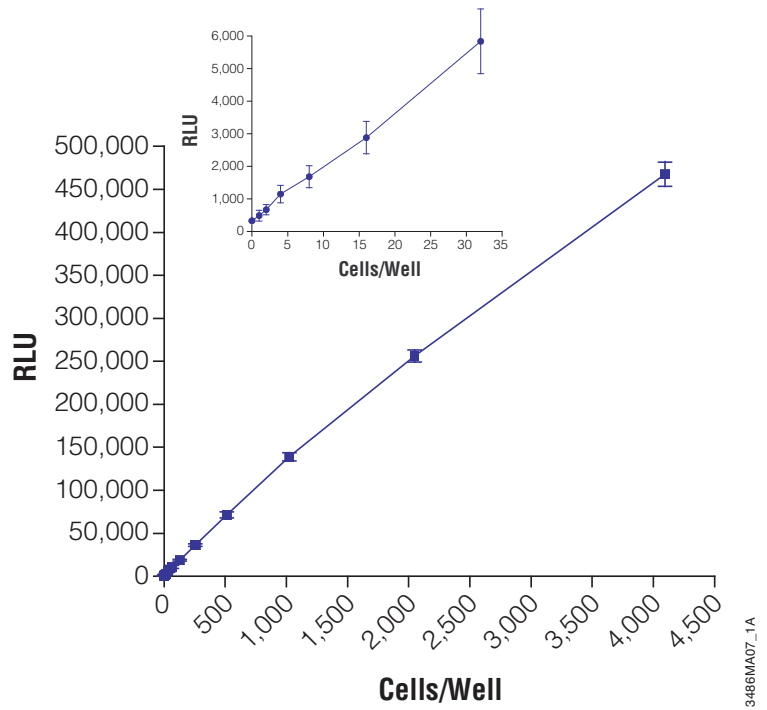

Fig. (2). ATP Assay Sensitivity. CellTiter-Glo ${ }^{\circledR}$ (Promega Corporation) was added and mixed with Jurkat cells in a 384 well plate. Luminescence was measured with a Wallac Victor ${ }^{\mathrm{TM}}$ after 10 minutes of incubation.

Despite an abundance of advantages for HTS implementation, ATP assays also carry liabilities. Because the ATPdependent luciferase reaction rate is susceptible to temperature flux, equilibration to constant room temperature is required to minimize thermal gradients created by plate well position (edge-effects). Also, like other metabolic assay chemistries used to measure viability, ATP is (rarely) subject to positive or negative modulation by test reagents independent of loss of viability leading to misleading data [39, 40]. Lastly, all commercial formulations of ATP-detection chemistries are susceptible to luciferase inhibition to various degrees by small molecule compounds. Recent evidence suggests that specific formulations may greatly minimize the extent of this inhibition [41].

\section{CYTOTOXICITY ASSAYS}

Cytotoxicity assay chemistries are formulated to detect loss of membrane integrity associated with cell death. The current most useful cytotoxicity biomarkers are constitutive, conserved and relatively stable, high-abundance enzymes "released" into the extra-cellular environment (culture medium) following loss of membrane integrity. Unlike viability assays whereby a decline in cell response is strongly inferred to be caused by cell-cycle arrest or death, detection of cytotoxic biomarker activities outside the cellular compartment after treatment is proof-positive for a compound's cytotoxic effect. Unfortunately, activity-based surrogates of cell death have a finite enzymatic half-life, which can limit their utility during long compound/cell contact incubations (48-72 hr) [3, 27]. Enzymatic decay as a function of time in culture medium can lead to underestimation of the absolute level of cytotoxicity [27]. The quantitative HTS (qHTS) approach eliminates a majority of this error because the kinetics of cytotoxicity is intrinsically linked to dose [42].

\section{LACTATE DEHYDROGENASE (LDH)}

LDH activity has a long history as a preferred marker for cell death with in vitro cell models [43, 44]. In HTS applications, the activity of LDH is indirectly measured by an enzymatically-coupled reagent chemistry comprised of lactate, $\mathrm{NAD}^{+}$, diaphorase and an appropriate redox dye such as a tetrazolium compound or resazurin. Although the result of LDH activity can be measured by a change in absorbance, fluorescence detection is favored because of greater sensitivity and the potential to miniaturize to high-density plates.

The implementation of LDH assays for cytotoxicity testing in HTS has been historically limited because most commercial assay protocols require a cell-free sample transferred into a separate assay plate. Reagents that are compatible with viable cells are available to detect release of $\mathrm{LDH}$, thus enabling a single addition homogeneous assay format [45]. Now LDH release can be routinely measured in HTS formats after a short incubation (10-20 minutes) using a fluorometer equipped with a $560 \mathrm{~nm}$ excitation source and a $590 \mathrm{~nm}$ collection filter (Fig. 3) [46].

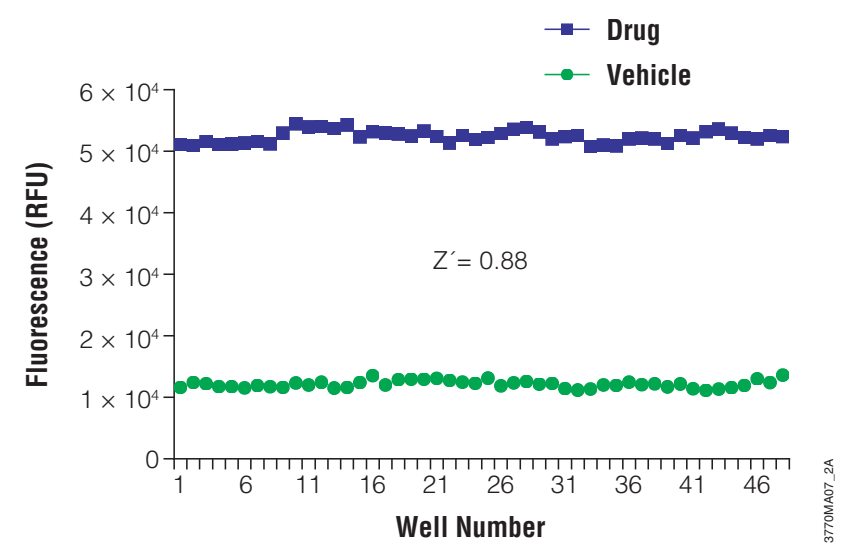

Fig. (3). LDH Assay Z'-factor Analysis. CytoTox-ONE ${ }^{\circledR}$ Assay reagent (Promega Corporation) was added to HepG2 cells treated with $3.125 \mu \mathrm{M}$ staurosporine. Medium served as vehicle control.

LDH assay detection is a robust and cost-effective means of assessing cytotoxicity, but is susceptible to background 
signal from serum sources of LDH found in supplemented growth media [47, 48]. Exogenous sources of LDH greatly elevate background values and negatively impact the overall signal window. This experimental detriment can be largely mitigated by careful pre-screening of serum sources for cell culture prior to $\mathrm{LDH}$ assay. $\mathrm{LDH}$ assays are also subject to assay artifacts by compounds that inhibit the LDH activity and by standard fluorescence and color quenching interferences [49-51].

\section{PROTEASE(S)}

A specific proteolytic profile associated with cell death has been recently identified and can be measured in a manner similar to LDH assays [26]. This method employs sequence-specific (Ala-Ala-Phe), fluorogenic or luminogenic peptide substrates delivered directly into assay wells via a buffered vehicle. The proteolytic activities present in viable cells are not detected by this method because normally compartmentalized proteases are not in contact with the impermeant substrates. However, protease(s) released into the culture medium as a result of cell death cleave the substrates releasing a detectible reporting molecule. The fluorescent format of the assay utilizes the highly-efficient rhodamine 110 (R110) fluorophore which is measured in as short as 30 minutes by a fluorometer with $485 \mathrm{~nm}$ excitation and 520 $30 \mathrm{~nm}$ emission filters $[52,53]$. The luminescent format employs an engineered luciferase formulation to detect the luciferin product of cleavage thereby generating a glow-type signal which peaks at 15-20 minutes, stably persists for 3-4 $\mathrm{hr}$, and is measured by standard luminometry.

Dead cell protease detection is advantageous in HTS and secondary screening applications because of improved sensitivity, linearity with respect to different degrees of cytotoxicity, reduction in background and artifactual hits, and choice in detection format (Fig. 4). These attributes allow the technology to be applied in 1536 well formats as easily as in lower density plates [54]. The dead cell protease detection method is subject to enzymatic activity decay due to the kinetics of cytotoxicity, biomarker inhibition, and standard interferences associated with the detection molecules.

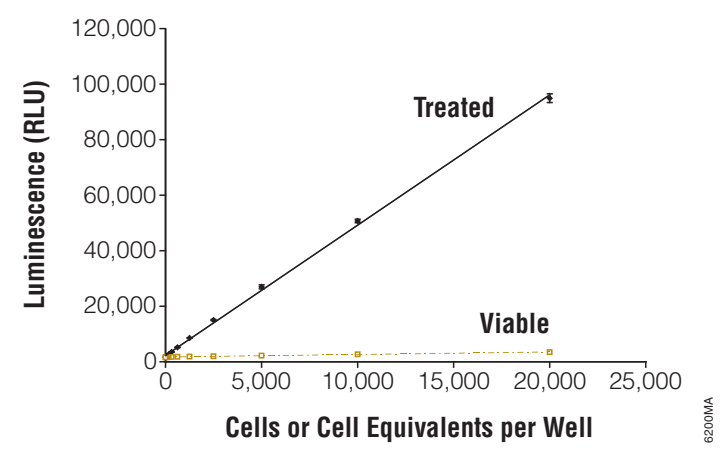

Fig. (4). Protease Assay Sensitivity and Linearity. CytoToxGlo $^{\mathrm{TM}}$ (Promega Corporation) was added to serial dilutions of viable and non-viable Jurkat cells and luminescence measured after 30 minutes.

\section{MULTIPLEXED VIABILITY AND CYTOTOXICITY ASSAYS}

The single parameter assays described above offer convenient and predictive methods to view the cytotoxic land- scape of chemical libraries. When certain combinations of the assays are added as same-well multiplexes however, they provide not only complementary but additive benefit [55]. Although the concept of multiplexed screening is well appreciated for image-based technologies, it is emerging as a more viable option for plate-based, homogeneous assays because implementation is simple, accessible, and cost effective [56].

Reagent compatibility is a major consideration in samewell multiplexing. There is an absolute requirement that individual signal readouts are distinct and can be parsed for meaningful data set analysis. Also, reagent formulations must not compromise functional aspects of the chemistries. For instance, lytic assays for ATP measurement or caspase activation must be conducted in a sequence-specific order after first measuring experimental cytotoxicity.

Several informative combinations of viability and cytotoxicity chemistries are currently employed in HTS formats to mitigate false determinations. These multiplexes address systematic error caused either by disparate cell numbers delivered to assay wells or random compound interferences with reporter molecules [55]. Except in cases of cell-cycle arrest prior to loss of membrane integrity, or long term exposure models, measures of viability and cytotoxicity are inversely proportional (Fig. 5). Therefore, non-conforming data sets can easily "flag" problem compounds for further analysis by orthogonal methods [57].

\section{FLUORESCENT/FLUORESCENT ASSAYS}

Several classic examples of fluorescent viability and cytotoxicity assays are known [58]. These methods rely on an impermeant DNA intercalating dye which labels cells with damaged membranes and a permeable dye that is sequestered inside viable cells after esterase cleavage of a labeling group. Variations of these traditional chemistries are rarely employed where total fluorescence from assay wells is measured, because of poor sensitivity from simple stoichiometric dye binding events in the non-viable cell population and requisite washes required for removal of unbound dye and serum-derived esterases. Stable, non-viable cell esterase activity is particularly problematic for assay utility as it greatly impacts assay background values and constricts signal windows.

A new, more amenable method for HTS environments combines the protease substrates for viability and cytotoxicity allowing for simultaneous measurement of viable and non-viable cell populations (Fig. 6). This method delivers broad linear responses $(0-50,000$ cells/well) and can measure as little as a $2 \%$ change in viability in both the AFC and R110 channels [59]. Furthermore, the reagent can be concentrated and delivered into assay wells in a substantially reduced volume to accommodate a third spectrally distinct reagent.

Triplexes created by uniting the fluorescent viability and cytotoxicity multiplex with luminescent chemistries are advantageous for several reasons. First, it is possible to conduct immediate confirmation testing of apparent cytotoxic compounds in the same well by leveraging the statistical power of orthogonal detection of viability (viable cell aminopeptidase, dead cell protease and ATP biomarkers). The economy of this consolidated testing is noteworthy in terms of 

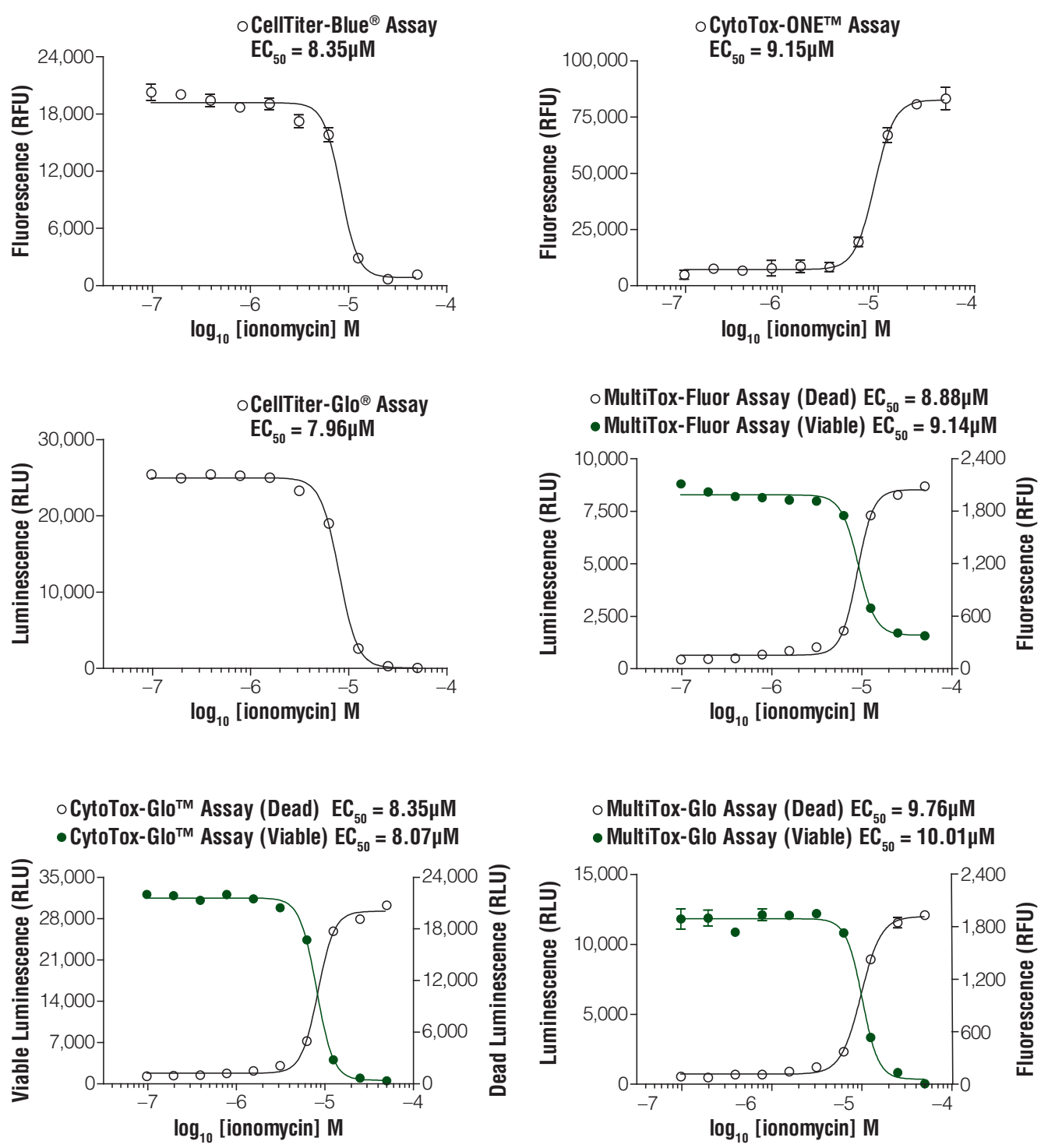

Fig. (5). Single- and Multi-parameter Viability and Cytotoxicity Assays. CellTiter-Blue ${ }^{\circledR}$, CytoTox-ONETM, CellTiter-Glo ${ }^{\circledR}$, MultiToxFluor, MultiTox-Glo and CytoTox-Glo ${ }^{\mathrm{TM}}$ Reagents (Promega Corporation) were added to Jurkat cells treated for $6 \mathrm{hr}$ with serial dilutions of ionomycin and signals measured as described in technical literature.

compound usage, culture set up, and operator man-hours. Second, the mechanism of cell death can often be elucidated when combined with caspase detection reagents, allowing for partial characterization of a compound's potential. It should be noted however, that caspase activity can be transient and immeasurable in long-term experiments due to the kinetics of apoptosis and caspase biomarker decay. Therefore, caspase-negative data sets should be rescreened at multiple compound exposure periods. This type of characterization of pathway dependent cytotoxicity is useful for continued annotation of a library, because compounds causing necrotic profiles at micromolar concentrations are rarely therapeutically useful and may offer unacceptable cytotoxic risk. And third, viability and cytotoxicity can be used to normalize luminescent data from other assays (Fig. 7). Single parameter genetic reporter responses are susceptible to experimental variation due to differential transfection efficiencies, cell number delivered to the well (clumping) or to cytotoxicity caused by the test compound [55]. Viability and cytotox- icity data can therefore help reconcile aberrant data points or explain decreases in genetic reporter signals due to cell death.

\section{FLUORESCENT/LUMINESCENT ASSAYS}

Mixed detection combinations of the protease biomarkers are also available that offer benefit in screening applications. In this method, viability is measured first by the addition of the GF-AFC reagent followed by the addition of the luminogenic dead cell reagent chemistry. The use of disparate detection platform methodologies is known to greatly reduce the statistical potential for assay interferences associated with reporter molecules [60]. Therefore this combination of chemistries is favored if a library is uncharacterized with regard to the relative abundance of luminogenic inhibitors or which may cause fluorescence interference. Unlike the fluorescence/fluorescence multiplex, fewer convenient triplex options exist. For example, the chemistry can be configured with a fluorogenic caspase activation chemistry (R110 
A.

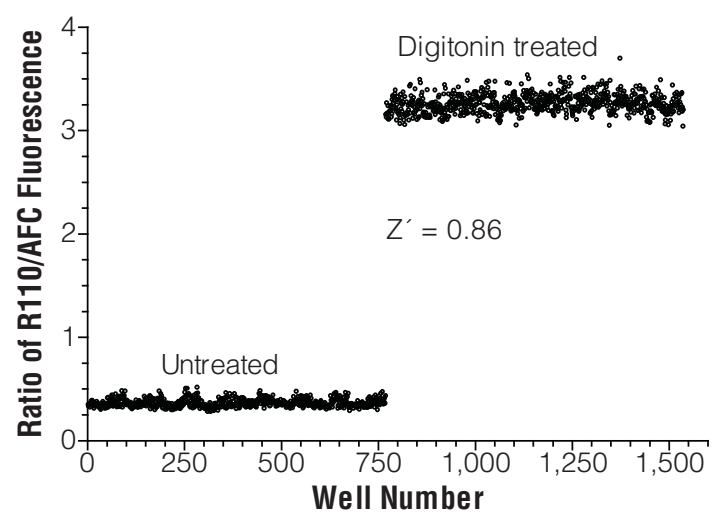

B.

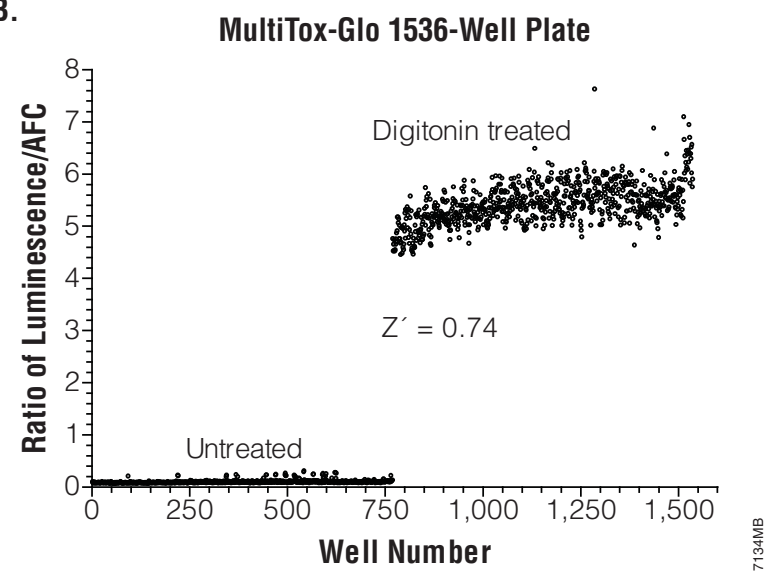

Fig. (6). Fluorescent/Fluorescent and Fluorescent Luminescent Viability and Cytotoxicity Assays. MultiTox-Fluor or MultiTox-Glo Reagents (Promega Corporation) were added to a 1536 well plate after Jurkat cells had been treated with $30 \mu \mathrm{g} / \mathrm{ml}$ digitonin or vehicle. Each well is represented as a ratio of the viable and non-viable values measured using the chemistries.

A.

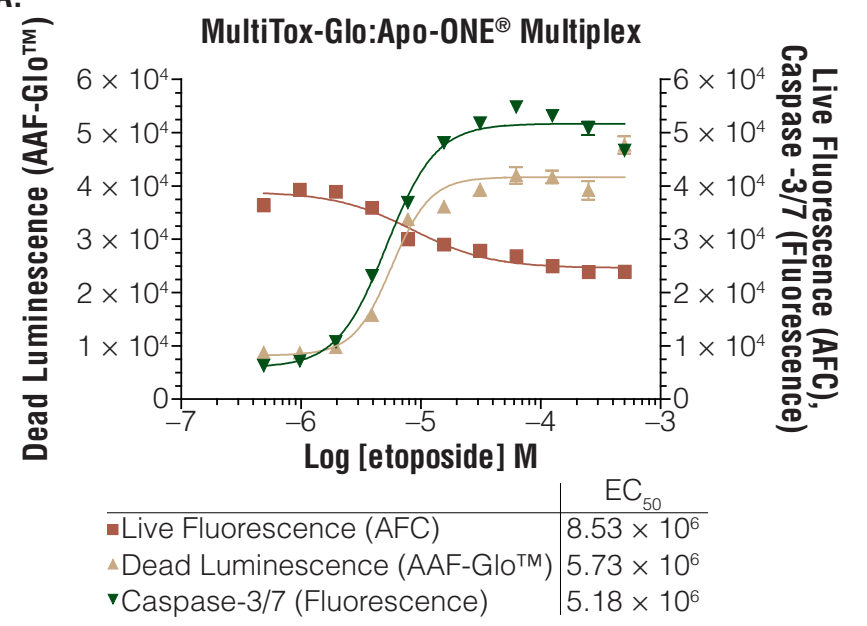

B.

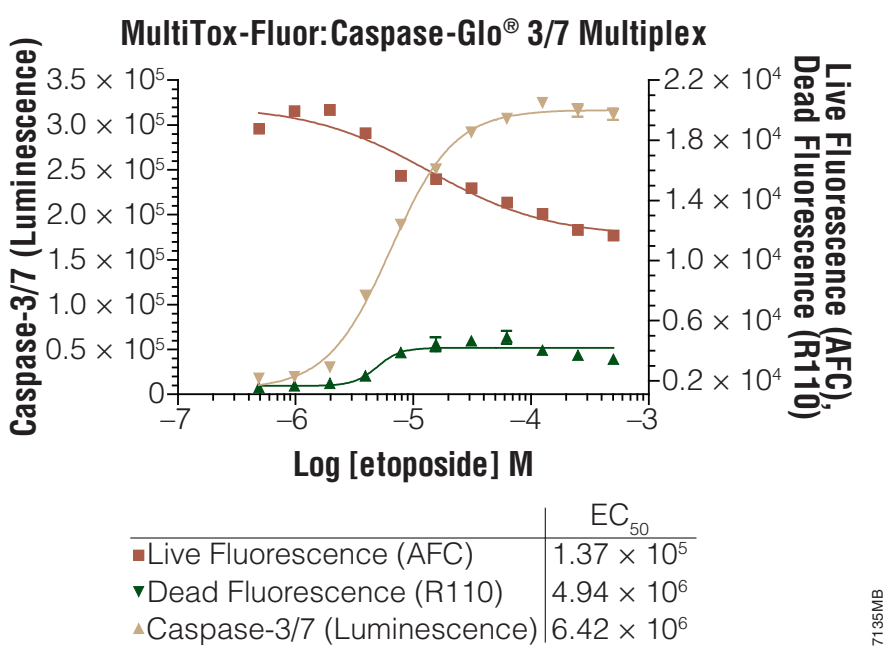

Fig. (7). Multi-Parametric Viability Assays Paired with Caspase Assays. Jurkat cells were plated in 384 well plates and treated with serial dosages of etoposide for 6hr. MultiTox-Fluor ${ }^{\mathrm{TM}}$ or MultiTox-Glo Reagents (Promega Corporation) were added to the plates and viability and cytotoxicity values measured. Apo-ONE ${ }^{\circledR}$ or Caspase-Glo ${ }^{\circledR}$ Reagents (Promega Corporation) were then added and caspase activation measured.

fluorophore) to deliver data relating to possible induction of apoptosis (Fig. 7A) [61, 62]. Again, negative caspase induction results should be verified by rescreening to verify necrotic response profiles.

\section{LUMINESCENT/LUMINESCENT ASSAYS}

Fully-luminescent formats are highly desirable for HTS environments because of the aforementioned advantages over fluorescent methods. Another remarkable feature of luminogenic assays is the persistent and stable glow-type signal produced after reagent addition (Fig. 8). This attribute can be harnessed to produce both viability and cytotoxicity values from the same well. In this method, the non-lytic, luminogenic cytotoxicity assay chemistry is first delivered to the assay well and cytotoxicity measured. Next, a lytic agent is added to assay wells to artificially release the remaining dead cell protease from viable cells. The net signal derived after complete lysis reflects the contribution of all the cells in the assay well. Because the luminescent signal is additive and proportional, the viable cell population can be indirectly determined by subtracting the cytotoxic values from the total values. This method is particularly useful for determining cytotoxicity in long incubation protocols where dead cell biomarker activity may not fully reflect actual cytotoxicity. One caveat of this method is that both viability and cytotoxicity measurements utilize the same biomarker and are subject to the same interferences.

\section{SUMMARY AND CONCLUSIONS}

In vitro cytotoxicity testing technologies for HTS continue their refinement on many fronts. High Content Screening (HCS) and label-free methods have gained some degree of popular following recently, but require expensive instrumentation, complicated analysis software packages and offer relatively low throughput. With burgeoning costs associated with drug discovery efforts, straight-forward, validated, homogeneous assay chemistries remain the choice as a simple and cost-effective means of assessing cytotoxic burden. 


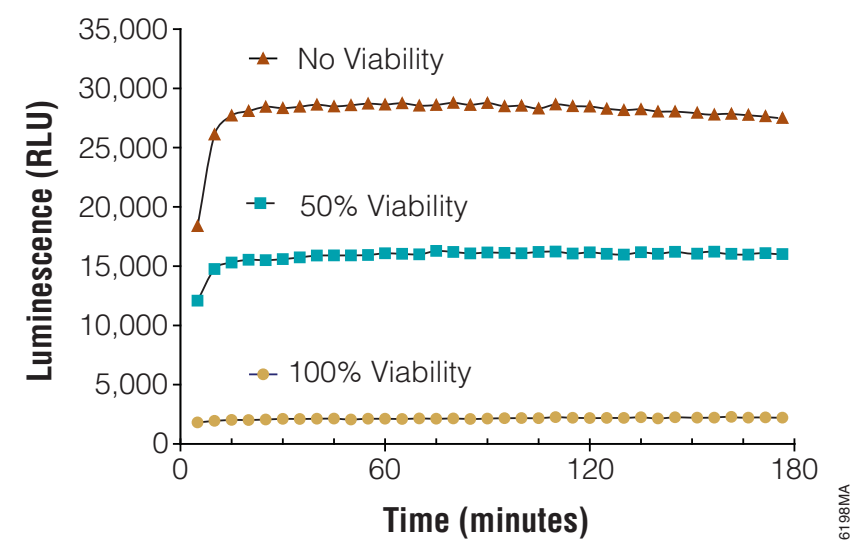

Fig. (8). Bioluminescent Protease Assay Signal. Stability CytoTox-Glo ${ }^{\mathrm{TM}}$ Reagent was added to blends of experimentally lysed and untreated HL-60 cells. Luminescence was measured using a BMG Polarstar ${ }^{\mathrm{TM}}$ in kinetic mode for $3 \mathrm{hr}$.

Depending upon the goals of the screen, either viability or true cytotoxicity assay chemistries can be employed. Cy- result (Table 2). Fluorescent formats require short to lengthy incubations with the sample whereas luminescent formats tend to deliver maximal signal windows in a rapid but prolonged fashion. Luminescent formats offer additional utility over fluorescent methods with regard to detection sensitivity, but are also typically more costly to use on a per well basis.

All assay chemistries are subject to experimental error or interferences which can lead to false interpretation of data sets. Multiplexed combinations of compatible assays offer a convenient and cost-effective manner to address variation (by response normalization), flag non-conforming orthogonal data points and increase per well content. Although greatly informative, special attention should be paid to experimental design and the interpretation of multiplexed data sets due to the transient or kinetic nature of mechanistic biomarkers.

\section{ACKNOWLEDGEMENT}

The authors would like to thank Michele Arduengo, $\mathrm{Ph} . \mathrm{D}$. for preparing and providing the figures for this work.

Table 2. Viability and Cytotoxicity Assay Reagents for HTS

\begin{tabular}{|c|c|c|c|c|c|c|}
\hline Assay Type & Reagent Name & Biomarker & $\begin{array}{l}\text { Detection } \\
\text { Method }^{Y}\end{array}$ & $\begin{array}{c}\text { Reagent Incubation } \\
\text { Period }\end{array}$ & $\begin{array}{l}\text { Sensitivity* } \\
\text { (cells/well) }\end{array}$ & $\begin{array}{c}\text { Multiplex } \\
\text { Options\# }\end{array}$ \\
\hline \multirow{3}{*}{ Viability } & CellTiter Blue $^{\circledR}$ & Reductase(s) & Fluorescence & 2-4 hrs & 50 & Yest \\
\hline & CellTiter-Fluor $^{\mathrm{TM}}$ & Protease(s) & Fluorescence & $30 \mathrm{~min}$ & $10-50$ & Yes \\
\hline & CellTiter-Glo $^{\circledR}$ & ATP & Luminescence & $10 \mathrm{~min}$ & 10 & Yest \\
\hline \multirow{3}{*}{ Cytotoxicity } & CytoTox-ONE & $\mathrm{LDH}$ & Fluorescence & $10 \mathrm{~min}$ & $\sim 200$ & Yes† \\
\hline & CytoTox-Fluor $^{\mathrm{rm}}$ & Protease(s) & Fluorescence & $30 \mathrm{~min}$ & $10-50$ & Yes \\
\hline & CytoTox-Glo $^{\mathrm{TM}}$ & Protease(s) & Luminescence & $15 \mathrm{~min}$ & 10 & Yest \\
\hline \multirow{3}{*}{$\begin{array}{c}\text { Viability } \\
\text { and } \\
\text { Cytotoxicity }\end{array}$} & MultiTox-Fluor & Protease(s) & $\begin{array}{l}\text { Fluorescence/ } \\
\text { Fluorescence }\end{array}$ & $30 \mathrm{~min}$ & $\begin{array}{l}10-50 / \\
10-50\end{array}$ & Yes \\
\hline & MultiTox-Glo & Protease(s) & $\begin{array}{l}\text { Fluorescence/ } \\
\text { Luminescence }\end{array}$ & $\begin{array}{l}30 \mathrm{~min} / \\
15 \mathrm{~min}\end{array}$ & $\begin{array}{c}10-50 / \\
10\end{array}$ & Yes \\
\hline & $\begin{array}{c}\text { CytoTox-Glo } \\
\text { With }\left(2^{\text {nd }} \text { step lysis }\right)\end{array}$ & Protease(s) & $\begin{array}{l}\text { Luminescence/ } \\
\text { Luminescence }\end{array}$ & $\begin{array}{l}15 \mathrm{~min} / \\
15 \mathrm{~min}\end{array}$ & $\begin{array}{c}10 / \\
10\end{array}$ & Yest \\
\hline
\end{tabular}

${ }^{\mathrm{q}}$ Detection method for combination viability and cytotoxicity assays is denoted as viability format/cytotoxicity format.

* Sensitivity was determined by limiting dilution series in the presence of $10 \%$ fetal bovine serum and is dependent upon cell type and instrumentation

${ }^{\dagger}$ Options exist, but may be assay sequence-dependent or require slight deviation from standard protocol.

totoxicity assays based on membrane integrity changes are positive-readout assays most typically indicated for shorterterm exposure models (48 $\mathrm{hr}$ or less). These assays may not always accurately estimate the absolute degree of early or late stage cytotoxicity due to the kinetics of biomarker emergence or degradation. Viability assays measure the level of biomarker activity inversely correlated with cytotoxicity and therefore may be used at any endpoint during a compound/cell incubation period.

Each biomarker of viability and cytotoxicity has advantages and disadvantages. The choice of which surrogate of health or death to use is greatly influenced by the available detection format and extent of assay time required to reach a

\section{REFERENCES}

[1] Rozman K, Doull J. Paracelsus, haber and arndt. Toxicology 2001; 160: 191-96.

[2] Horvath S. Cytotoxicity of drugs and diverse chemical agents to cell cultures. Toxicology 1980; 16: 59-66.

[3] Riss T, Moravec R. Use of multiple assay endpoints to investigate the effects of incubation time, dose of toxin, and plating density in cell-based cytotoxicity assays. Assay Drug Dev Technol 2004; 2: 51-62.

[4] Slim R, Toborek M, Robertson L, et al. Cellular glutathione status modulates polychlorinated biphenyl-induced status and apoptosis in vascular endothelial cells. Toxicol Appl Pharm 2000; 166(1): 3642. 
[5] Svingen PA, Loegering D, Rodriguez J, et al. Components of the cell death machine and drug sensitivity of the National Cancer Institute Cell Line Panel. Clin Cancer Rev 2004; 10: 6807-20.

[6] Slee EA, Harte MT, Cluck RM, et al. Ordering the Cytochrome cintitated caspase cascade: heirarchial activation of caspases-2,-3,$6,-7,-8$, and -10 in a caspase-9 dependent manner. J Cell Biol 1999, 144(2): 281-92.

[7] Cook J, Mitchell J. Viability measurements in mammalian cell systems. Anal Biochem 1989; 179: 1-7.

[8] Borenfreund E, Puerner J. Toxicity determined in vitro by morphological alterations and neutral red adsorption. Toxicol Lett 1985; 24: 119-24.

[9] Rose D, Lemmo T. Challenges in implementing high density formats for high throughput screening. Lab Autom News 1997; 2: 1219.

[10] Maffia A, Kariv I, Oldenburg K. Miniaturization of a mammalian cell-based assay: luciferase reporter gene readout in a 3 microliter 1536-well plate. J Biomol Screen 1999; 4: 137-42.

[11] Nicotera P, Leist M, Manzo L. Neuronal cell death: a demise with different shapes. Trends Pharmacol Sci 1999; 20: 46-51.

[12] Rixe O, Fojo T. Is cell death a critical end point for anticancer therapies or is cytostasis sufficient? Clin Cancer Res 2007; 13(24): 7280-87.

[13] Shi W, Gould MN. Induction of cytostasis in mammalian carcinoma cells treated with the anticancer agent perillyl alcohol. Carcinogenesis 2002; 23: 131-42.

[14] O'Brien J, Wilson I, Orton T, et al. Investigation of the Alamar Blue (resazurin) fluorescent dye for the assessment of mammalian cell cytotoxicity. Eur J Biochem 2000; 267: 5421-26.

[15] Page B, Page M, Noel C. A new fluorometric assay for cytotoxicity measurements in vitro. Int J Oncol 1993; 3: 473-76.

[16] Roehm N, Rodgers G, Hatfield S, et al. An improved colorimetric assay for cell proliferation and viability utilizing the tetrazolium salt XTT. J Immunol Methods 1991; 142: 257-65.

[17] Barltrop J, Owen T. 5-(3-carboxymethoxyphenyl)-2-(4,5-dimethylthiazoly)-3-(4-sulfophenyl)tetrazolium, inner salt (MTS) and related analogs of 3-(4,5-dimethylthiazolyl)-2,5-diphenyltetra-zolium bromide (MTT) reducing to purple water-soluble formazans as cellviability indicators. Bioorg Med Chem Lett 1991; 1: 611-14.

[18] Cory A, Owen T, Barltrop J, et al. Use of an aqueous soluble tetrazolium/formazan assay for cell growth assays in culture. Cancer Commun 1991; 3: 207-12.

[19] Shum D, Radu C, Kim E, et al. A high density assay format for he detection of novel cytotoxic agents in large chemical libraries. J Enz Inhib Med Chem 2008; 23(6): 931-45.

[20] Hamid R, Rotshteyn Y, Rabadi L, et al. Comparison of alamar blue and MTT assays for high through-put screening. Toxicol In Vitro 2004; 18: 703-10.

[21] Miret S, De Groene E, Klaffke W. Comparison of in vitro assays of cellular toxicity in the human hepatic cell line HepG2. J Biol Screen 2006; 11: 184-93.

[22] Ulukaya E, Ozdikicioglu F, Yilmaztepe-Oral A, et al. The MTT assay yields a relatively lower result of growth inhibition than the ATP assay depending on the chemotherapeutic drugs tested. Toxicol In Vitro 2008; 22: 232-39.

[23] Pagliacci M, Spinozzi F, Migliorati G, et al. Genistein inhibits tumour cell growth in vitro but enhances mitochondrial reduction of tetrazolium salts: a further pitfall in the use of the MTT assay for evaluating cell growth and survival. Eur J Cancer 1993; 29: 157377.

[24] Collier A, Pritsos C. The mitochondrial uncoupler dicumerol disrupts the MTT assay. Biochem Pharm 2003; 66: 281-87.

[25] Squatrito R, Connor J, Buller R. Comparison of a novel redox dye cell growth assay to the ATP bioluminescence assay. Gynecol Oncol 1995; 58: 101-05.

[26] Niles A, Moravec R, Hesselbeth P, et al. A homogeneous assay to measure live and dead cells in the same sample by detecting different protease markers. Anal Biochem 2007; 366: 197-206.

[27] Niles A, Moravec R, Riss T. Update on in vitro cytotoxicity assays for drug development. Expert Opin Drug Discov 2008; 3(6): 65569.

[28] Niles A, Worzela T, Scurria M, et al. Multiplexed viability, cytotoxicity and apoptosis assays for cell-based screening. Cell Notes 2006; 16: 12-15.

[29] Turek-Etienne T, Lei M, Terracciano J, et al. Use of red-shifted dyes in a fluorescence polarization AKT kinase assay for detection of biological activity in natural product extracts. J Biomol Screen 2004; 9: 52 - 61 .

[30] Crouch S, Kozlowski R, Slater K, et al. The use of ATP bioluminescence as a measure of cell proliferation and cytotoxicity. J Immunol Methods 1993; 160: 81-8.

[31] Lundin A. Estimation of biomass in growing cell lines by ATP assay. Methods Enzymol 1986; 133: 27-42.

[32] Maehara Y, Anai H, Tamada R, et al. The ATP assay is more sensitive than the succinate dehydrogenase inhibition test for predicting cell viability. Eur J Cancer Clin Oncol 1987; 23: 273-76.

[33] Slater K. Cytotoxicity tests for high-throughput drug discovery. Cur Opin Biotechnol 2001; 12: 70-4.

[34] Hall M, Gruber M, Hannah R, et al. Stabilization of firefly luciferase using directed evolution. In: Bioluminescence and Chemiluminescence-Perspectives for the 21st Century. Roda A, Pazzagli M, Kricka L, et al. Eds., Chichester, UK: John Wiley \& Sons 1998; pp. 392-395.

[35] Riss T. Selecting cell-based assays for drug discovery screening. Cell Notes 2005; 13: 16-21.

[36] Severson W, Shindo N, Sosa M, et al. Development and validation of a high-throughput screen for inhibitors of SARS CoV and its application in screening of a 100,000-compound library. J Biomol Screen 2007; 12: 33-40.

[37] Borawski J, Lindeman A, Buxton F, et al. Optimization procedure for small interfering RNA transfection in a 384-well format. J Biomol Screen 2007; 12: 546-59.

[38] Fan F, Wood K. Bioluminescent assays for high-throughput screening. Assay Drug Dev Technol 2007; 5: 127-36.

[39] Sanchez-Alcazar J, Ruiz-Cabello J, Hernandez-Munoz I, et al. Tumor necrosis factor- $\alpha$ increases ATP content in metabolically inhibited L929 cells preceding cell death. J Biol Chem 1997; 272: 30167-77.

[40] Shchepina L, Pletjushhkina O, Averisyan A, et al. Oligomycin, inhibitor of the $\mathrm{F}_{\mathrm{o}}$ part of $\mathrm{H}^{+}$-ATP synthase, suppresses the TNFinduced apoptosis. Oncogene 2002; 21: 8149-57.

[41] Kashem M, Nelson R, Yingling J, et al. Three mechanistically distinct kinase assays compared: measurement of intrinsic ATPase activity identified the most comprehensive set of ITK inhibitors. J Biomol Screen 2007; 12: 70-83.

[42] Xia M, Huang R, Witt K, et al. Compound cytotoxicity profiling using quantitative high-throughput screening. Environ Health Perspect 2008; 116(3): 284-91.

[43] Korzeniewski C, Callewaert D. An enzyme-release assay for natural cytotoxicity. J Immunol Methods 1983; 64: 211-24.

[44] Decker T, Lohmann-Matthes M. A quick and simple method for the quantification of lactate dehydrogenase release in measurements of cellular cytotoxicity and tumor necrosis factor (TNF) activity. J Immunol Methods 1988; 115: 61-9.

[45] Riss T, Moravec R. Introducing the CytoTox-ONE homogeneous membrane integrity assay. Cell Notes 2002; 4: 6-9.

[46] Bakshi P, Liao Y-F, Gao J, et al. A high-throughput screen to identify inhibitors of amyloid B-protein precursor processing. J Biomol Screen 2005; 10: 1-12.

[47] Pei J, Ficht T. Brucella abortus rough mutants are cytopathic for macrophages in culture. Infect Immun 2004; 72: 440-50.

[48] Hasinoff B, Schroeder P, Patel D. The metabolites of the cardioprotective drug dexrazoxane do not protect myocytes from doxorubicin-induced cytotoxicity. Mol Pharmacol 2003; 64: 67.

[49] Anderson B, Noble C. In vitro inhibition of lactate dehydrogenases by kepone. J Agric Food Chem 1977; 25: 8-31.

[50] Sanders G, van der Neut E, Straalen J. Inhibition of lactate dehydrogenase isoenzymes by sodium perchlorate evaluated. Clin Chem 1990; 36: 1964-66.

[51] Lash L, Zalups R. Mercuric chloride-induced cytotoxicity and compensatory hypertrophy in rat kidney proximal tubular cells. J Pharmacol Exp Ther 1992; 261: 819-29.

[52] Liu J, Bhalgat M, Zhang C, et al. Fluorescent molecular probes V: a sensitive caspase-3 substrate for fluorometric assays. Bioorg Med Chem Lett 1999; 9: 3231-36.

[53] Leytus S, Melhado L, Mangel W. Rhodamine-based compounds as fluorogenic substrates for serine proteinases. Biochem J 1983; 209: 299-307.

[54] Cho M-H, Niles A, Huang R, et al. A bioluminescent cytotoxicity assay for assessment of membrane integrity using a proteolytic biomarker. Toxicol In Vitro 2008, 22: 1099-106. 
[55] Hallis T, Kopp A, Gibson J, et al. An improved $\beta$-lactamase reporter assay: multiplexing with a cytotoxicity readout for enhanced accuracy of hit identification. J Biomol Screen 2007; 12: 635-44.

[56] Gerets HJ, Hanon E, Cornet M, et al. Selection of cytotoxicity markers for the screening of new chemical entities in a pharmaceutical context: a preliminary study using a multiplexing approach. Toxicol In Vitro 2009; 23: 319-32.

[57] Niles A, Scurria M, Bernad L, et al. Measure relative numbers of live and dead cells and normalize assay data to cell number. Cell Notes 2007; 18: 15-20.

[58] Papadopoulous N, Dedoussis G, Spanakos G, et al. An improved fluorescence assay for the determination of lymphocyte-mediated cytotoxicity using flow cytometry. J Immunol Methods 1994; 177: 101-11.

[59] Niles A, Moravec R, Scurria M, et al. MultiTox-fluor multiplex cytotoxicity assay technology. Cell Notes 2006; 15: 11-15.

[60] Grant S, Sklar J, Cummings R. Development of novel assays for proteolytic enzymes using rhodamine-based fluorogenic substrates. J Biomol Screen 2002; 7: 531-40.

[61] Worzella T, Busch M, Niles A. High throughput automation of multiplexed cell viability assays for viability and cytotoxicity. Cell Notes 2008; 20: 26-9.

[62] Niles A, Moravec R, Riss T. Multiplex caspase activity and cytotoxicity assays. Methods Mol Biol 2008; 414: 151-62.

Received: March 02, 2009

Revised: April 04, 2009

Accepted: April 17, 2009

(C) Niles et al.; Licensee Bentham Open.

This is an open access article licensed under the terms of the Creative Commons Attribution Non-Commercial License (http://creativecommons.org/licenses/by-nc/3.0/) which permits unrestricted, non-commercial use, distribution and reproduction in any medium, provided the work is properly cited. 